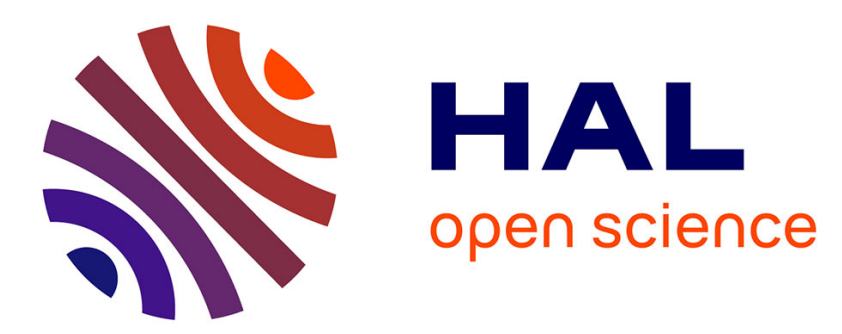

\title{
High-power Yb:YAG single-crystal fiber amplifiers for femtosecond lasers in cylindrical polarization
}

Fabien Lesparre, Jean Thomas Gomes, Xavier Delen, Igor Martial, Julien

Didierjean, Wolfgang Pallmann, Bojan Resan, Michael Eckerle, Thomas Graf, Marwan Abdou Ahmed, et al.

\section{To cite this version:}

Fabien Lesparre, Jean Thomas Gomes, Xavier Delen, Igor Martial, Julien Didierjean, et al.. Highpower Yb:YAG single-crystal fiber amplifiers for femtosecond lasers in cylindrical polarization. Optics Letters, 2015, 40 (11), pp.2517-2520. 10.1364/OL.40.002517 . hal-01179174

\section{HAL Id: hal-01179174 \\ https://hal-iogs.archives-ouvertes.fr/hal-01179174}

Submitted on 23 Jul 2015

HAL is a multi-disciplinary open access archive for the deposit and dissemination of scientific research documents, whether they are published or not. The documents may come from teaching and research institutions in France or abroad, or from public or private research centers.
L'archive ouverte pluridisciplinaire HAL, est destinée au dépôt et à la diffusion de documents scientifiques de niveau recherche, publiés ou non, émanant des établissements d'enseignement et de recherche français ou étrangers, des laboratoires publics ou privés. 


\title{
High-power Yb:YAG single-crystal fiber amplifiers for femtosecond lasers in cylindrical polarization
}

\author{
Fabien Lesparre ${ }^{1,2}$, Jean Thomas Gomes ${ }^{1}$, Xavier Délen ${ }^{1,}$ Igor Martial $^{2}$, Julien Didierjean ${ }^{2}$, Wolfgang Pallmann ${ }^{3}$, \\ Bojan Resan ${ }^{3}$, Michael Eckerle ${ }^{4}$, Thomas Graf ${ }^{4}$, Marwan Abdou Ahmed ${ }^{4}$, Frederic Druon ${ }^{1}$, \\ François Balembois $^{1}$, Patrick Georges ${ }^{1}$ \\ ${ }^{I}$ Laboratoire Charles Fabry, UMR 8501, Institut d'Optique, CNRS, Univ Paris Sud, 2 Avenue A. Fresnel, 91127 Palaiseau Cedex, France \\ ${ }^{2}$ Fibercryst SAS, Parc d'activité Wilson Bât A1, 31 Rue Wilson, F-69150 Decines Charpieu, France \\ ${ }^{3} J D S U$ Ultrafast Lasers AG, Ruetistrasse 12, 8952 Schlieren, Switzerland \\ ${ }^{4}$ Institut für Strahlwerkzeuge, Universität Stuttgart, Pfaffenwaldring 43, 70569 Stuttgart, Germany \\ *Corresponding author: fabien.lesparre@institutoptique.fr
}

Received Month X, XXXX; revised Month X, XXXX; accepted Month X,

XXXX; posted Month X, XXXX (Doc. ID XXXXX); published Month X, XXXX

\begin{abstract}
We demonstrate a three-stage diode-pumped Yb:YAG single-crystal-fiber amplifier to generate femtosecond pulses at high average powers with linear or cylindrical (i.e. radial or azimuthal) polarization. At a repetition rate of $20 \mathrm{MHz}, 750 \mathrm{fs}$ pulses were obtained at an average power of $85 \mathrm{~W}$ in cylindrical polarization and at $100 \mathrm{~W}$ in linear polarization. The report includes investigations on the use of $\mathrm{Yb}$ :YAG single-crystal-fibers with different length/doping ratio and the zerophonon pumping at a wavelength of $969 \mathrm{~nm}$ in order to optimize the performance.

OCIS Codes: (140.0140) Lasers and laser optics; (140.3280) Laser amplifiers; (260.5430) Polarization; Ultrafast lasers (140.7090).
\end{abstract}

In the last decade laser beams with cylindrical polarization states, namely radial and azimuthal polarizations, have sparked increasing interest. Radially and azimuthally polarized laser beams have unique properties that are advantageous for a wide range of applications, including laser material processing. The isotropic properties of the polarization state increase cutting speed and lead to higher aspect ratio holes with improved symmetry for drilling [1], and reduce spattering in welding applications [2]. Moreover, the doughnut-like intensity distribution of cylindrically polarized beams exhibit steeper slopes than Gaussian beams, which leads to higher processing quality with sharper edges and higher process efficiencies. Therefore, it becomes very interesting to implement the cylindrical polarization also in ultrafast systems dedicated to micromachining. Cylindrically polarized laser beams can directly be generated within a laser cavity or by converting linearly polarized beams by means of an extra-cavity polarization converter [3-7]. In the latter case, easy-to-implement and robust segmented-wave-plates can be used [8], which are particularly well adapted to high average powers and allows to decrease the constraints on the oscillator, which is especially important for femtosecond oscillators. The master oscillator power amplifier (MOPA) scheme therefore is a very convenient approach to combine cylindrical polarization, high average power and ultrashort pulses.

Yb-doped diode-pumped solid-state lasers (DPSSL) in MOPA configuration clearly dominate the field of high average power ultrafast lasers. Among the geometries used so far for high-power Yb-doped DPSSL as slabs $[9,10]$, rods [11] and thin disks [12], the single crystal fiber
(SCF) technology was recently shown to have a high potential for the amplification of ultrashort pulses thanks to a very efficient thermal management and high optical efficiencies. This technology combined with the cubic crystal structure of $\mathrm{Yb}: \mathrm{YAG}$ offers a cylindrical symmetry of the optical and thermo-mechanical properties. Yb:YAG SCFs are therefore well suited for the amplification of cylindrically polarized beams.

CW beams with radial and azimuthal polarization have recently successfully been amplified up to a power of 100 $\mathrm{W}$ in an Yb:YAG SCF [13]. Here we now report on the use of an SCF to directly amplify femtosecond pulses in a passive MOPA to achieve high energy and high average power pulses with radial and azimuthal polarizations without any stretching and recompression of the pulses.

The experimental setup is schematically shown in Fig. 1. The seed laser oscillator provided 360 fs pulses at a repetition rate of $20 \mathrm{MHz}$ with an average power of $1.5 \mathrm{~W}$ and a spectral width of $3.45 \mathrm{~nm}$ FWHM centered at a wavelength of $1031 \mathrm{~nm}$.

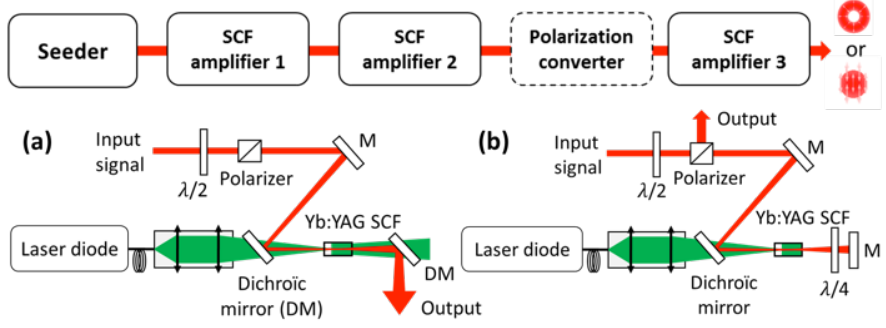

Fig. 1. Experimental setup. (a) single-pass configuration setup. (b) double-pass configuration setup. 
The amplifier consisted of three Yb:YAG SCF TARANIS modules. The implementation of the three separate SCF amplifier stages was an opportunity to investigate different solutions with respect to the pumping diode, gain media, and setup configuration in order to optimize the overall performance. The setup is composed of two Yb:YAG SCF pre-amplifiers operating in linear polarization to favor high gain amplification, and a last amplifier stage operating in radial/azimuthal polarization achieved by adding the polarization converter at the input.

The first amplifier is designed to operate with high gain. In this regards the SCF is operated in doublepass configuration as presented in Fig. 1(b) and is pumped by a high-brightness diode delivering $120 \mathrm{~W}$ of power at a wavelength of $940 \mathrm{~nm}$ through a fiber with a core diameter of $200 \mu \mathrm{m}$ and a NA of 0.22 . The pump fiber output is imaged to a spot diameter of $400 \mu \mathrm{m}$ a few $\mathrm{mm}$ inside the SCF which had a diameter of $1 \mathrm{~mm}$. After the oscillator being optically isolated, a half wave plate and a polarizer are used to control the incident signal power. A dichroic mirror which is transmitting the pump beam (at $940 \mathrm{~nm}$ ) is used to reflect the signal (at $1031 \mathrm{~nm}$ ) into the SCF. The double-pass of the beam is realized by a quarterwave-plate placed after the SCF in order to obtain a $90^{\circ}$ rotation of the polarization between the first and the second pass. A polarizer separates the output from the input beam after the second pass.

Two different $\mathrm{Yb}$ :YAG SCF, a standard one with a length of $40 \mathrm{~mm}$ and with 1 at. $\%$ of doping concentration and a custom one with a length of 30 $\mathrm{mm}$ and 2 at. $\%$ of doping concentration, have been tested for optimization purposes. According to our calculations the latter was expected to have the optimum length/doping ratio for the first amplifier stage. Fig. 2 shows the output powers of the first amplifier versus pump power for both single and double pass configuration and for each of the two SCF. For an input average power of $1.1 \mathrm{~W}$ and a pump power of $120 \mathrm{~W}$ the $30 \mathrm{~mm}$ long and $2 \%$ doped SCF produces an average power of $9,2 \mathrm{~W}$ in single pass and up to $22 \mathrm{~W}$ in double pass configuration. This represents an increase of $63 \%$ compared to the output power obtained with the $40 \mathrm{~mm}$ long and $1 \%$ doped SCF. In the optimized configuration, the double pass gain is then 20 and the slope efficiency $18 \%$. At the maximum pump power a beam quality factor $\mathrm{M}^{2}$ of 1.1 was measured in both directions.

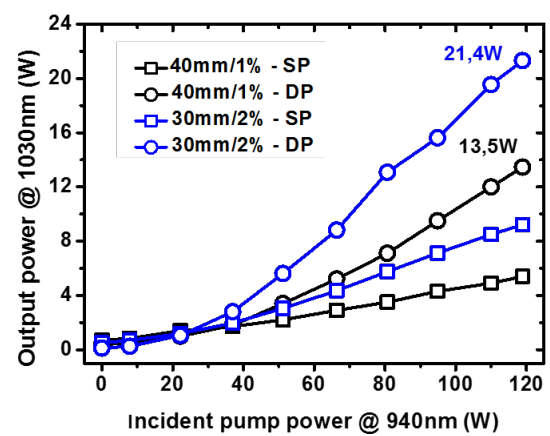

Fig. 2. Output power versus pump power in single-pass and double-pass for the standard and the optimized SCF. $\mathrm{SP}=$ Simple Pass, $\mathrm{DP}=$ Double Pass.

In order to achieve higher extraction levels, a more powerful laser diode delivering $200 \mathrm{~W}$ is used for the second stage. The two pumping wavelengths $969 \mathrm{~nm}$ and $940 \mathrm{~nm}$ were tested to investigate the impact on the thermal issues. Pumping into the zero-phonon transition at $969 \mathrm{~nm}$ theoretically reduces the thermal load by $30 \%$ as compared to pumping at 940 $\mathrm{nm}$ while preserving the absorption efficiency in the SCF. The price to pay is wavelength stabilization and spectral narrowing of the pump diode since the absorption line at $969 \mathrm{~nm}$ is narrower $(\sim 2 \mathrm{~nm})$ than at $940 \mathrm{~nm}(>15 \mathrm{~nm})$. In our case the $969 \mathrm{~nm}$ diode is stabilized using a volume Bragg grating (VBG). For fair test comparison, in both cases, the diode emits up to $150 \mathrm{~W}$ in a $200-\mu \mathrm{m}, 0.22-\mathrm{NA}$ fiber. The amplified output power obtained from a $40 \mathrm{~mm}$ long SCF with 1 at. \% of doping SCF in single pass configuration with a signal input power of $15 \mathrm{~W}$ is shown in Figure 3(a). For pump powers lower than $120 \mathrm{~W}$ there is no significant difference between the pumping at the two wavelengths, neither in terms of average output power nor with respect to beam quality. Above $120 \mathrm{~W}$ the performance starts to be different, the output power continues to grow linearly with increasing pump power at $969 \mathrm{~nm}$ whereas there is a rollover when pumping at $940 \mathrm{~nm}$.

As the output power of our $940 \mathrm{~nm}$ diode is limited to $150 \mathrm{~W}$, investigations at higher powers were carried out only with the $969 \mathrm{~nm}$ diode. At $200 \mathrm{~W}$ of pump power, the output power extracted from the amplifier is $52 \mathrm{~W}$ with a still constant slope efficiency of $20 \%$. To further increase the output power the amplifier was also used in a double pass configuration (Fig. 1(b)). Figure 3(b) compares the results for single and double pass configuration pumped at $969 \mathrm{~nm}$. For an input signal power of 15 $\mathrm{W}, 72 \mathrm{~W}$ of output is obtained which corresponds to a gain of 4.8. The beam quality was measured to be $\mathrm{M}^{2}$ $=1.18$ and $\mathrm{M}^{2}=1.21$ in vertical and horizontal direction, showing that there is no significant degradation. 

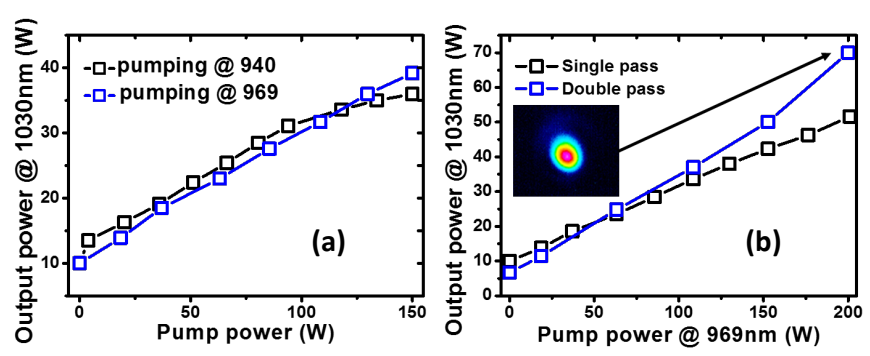

Fig. 3. (a) Comparison of pumping at $940 \mathrm{~nm}$ and $969 \mathrm{~nm}$ for $15 \mathrm{~W}$ of incident signal power. (b) Performance obtained in single and double pass when pumping at $969 \mathrm{~nm}$.

As the double pass configuration is not compatible with cylindrical polarization, the polarization converter is placed after the second SCF amplification stage as shown Fig. 1. The polarization converter consists of an assembly of 8 half-wave plate segments. By a proper alignement of the main axis of the converter relative to the axis of the incoming linear polarization one can convert the beam either to radial or azimuthal polarization. The intensity distribution is slightly distorted by diffraction effects at the junctions of the wave-plates. In order to obtain a clean $\mathrm{LG}_{01}$ intensity distribution and to remove the scattered light from the edges of the wave-plates spatial filtering is implemented by focusing the beam through a pinhole with a diameter of $100 \mu \mathrm{m}$. The losses of the converter and the spatial filter are $20 \%$ leading to a decrease of the power from 72 to $55 \mathrm{~W}$. The third single-pass SCF amplifier allows to compensate for these losses and test the amplification of radially/azimuthally polarized beams. The $\mathrm{Yb}$ :YAG SCF within this last stage is 40 $\mathrm{mm}$ long with 1 at. \% of doping and has a diameter of $1 \mathrm{~mm}$. It is pumped by a laser diode coupled to a $200-\mu \mathrm{m}$ fiber emitting up to $120 \mathrm{~W}$ of power at $940 \mathrm{~nm}$. The waist diameter of the signal beam inside the SCF is $500 \mu \mathrm{m}$. As shown in Fig 4, the amplified signal beam reaches a maximum power of $86 \mathrm{~W}$ for both radially and azimuthally polarized seed beams. This corresponds to a single pass gain of 1.5 and an extraction efficiency of $26 \%$.

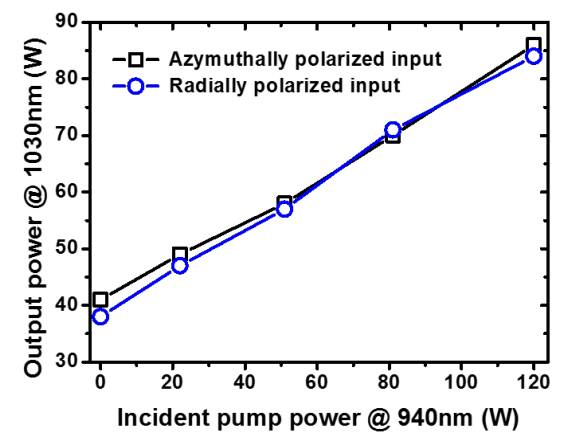

Fig. 4. Output power versus pump power in single-pass for both radially and azimuthally polarized input beam.
In order to confirm the quality of the radial or azimuthal polarization state of the amplified beam and to demonstrate the absence of depolarization, a linear polarizer was placed in the output beam and the transmitted intensity distribution was measured with a CCD camera as shown in Fig. 5. Two lobes of the intensity distribution can be observd, changing azimuthal position when rotating the analyzer axis (Fig. 5(c-f)), which confirms the excellent quality of the cylindrical polarization.

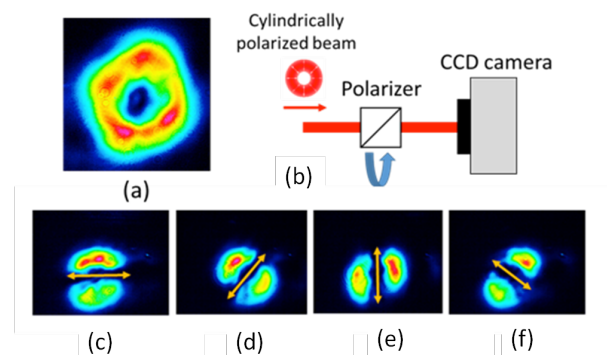

Fig. 5. (a) Far-field intensity distribution of the amplified beam. (b) Experimental setup used to analyze the polarization quality. (c-f) Intensity distributions with rotation of the analyzer axis.

Figure 6 shows the optical spectrum of the amplified pulses at different stages of the amplification process. The gain narrowing progressively affects the optical spectrum by decreasing the FWHM from $3.45 \mathrm{~nm}$ to $1.7 \mathrm{~nm}$. Consequently the pulse duration increases during the amplification. The cylindrically polarized output pulses were characterized by a second-harmonic generation autocorrelator. Pulse durations of $740 \mathrm{fs}$ were measured assuming a sech $^{2}$ temporal shape. This corresponds to a time-bandwidth product of 0.36 (Fig. 6). The pulse energies and peak power reach 4.2 $\mu \mathrm{J}$ and $5 \mathrm{MW}$, respectively.
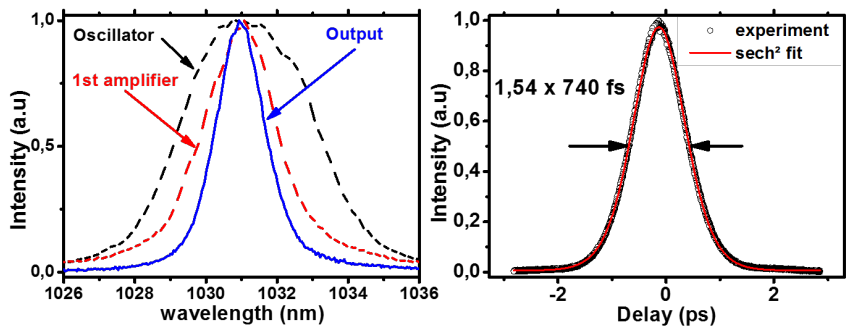

Fig. 6. Spectrum of the output pulses for three gain values (left). Autocorrelation trace of the output pulses (right).

Additional experiments were conducted to evaluate the maximum average power reachable with the third SCF amplifier stage in linear polarization by removing the polarization converter from the setup. The power incident to the third SCF was set to $55 \mathrm{~W}$ which corresponds to a pulse energy of $2.75 \mu \mathrm{J}$ (at a repetition rate of $20 \mathrm{MHz}$ ) and peak power of $4 \mathrm{MW}$ for a pulse duration of $700 \mathrm{fs}$. At this level of peak 
power, self-focusing induced by Kerr effect starts to be an issue as it leads to a reduction of the beam diameter on the output facet and can lead to coating damages. To overcome this limitation, we used a shorter SCF for these experiments. It was $1 \mathrm{~mm}$ in diameter, $30 \mathrm{~mm}$ long, and was doped with 1 at. \%. As shown in Fig. 7, the amplified beam reaches up to $100 \mathrm{~W}$ of power with a thermal depolarization rate below $4 \%$. This corresponds to a single pass gain of 1.8 and an extraction efficiency of $38 \%$. The pulse energy and peak power reached $5 \mu \mathrm{J}$ and $7 \mathrm{MW}$, respectively. The spectral bandwidth is $1.8 \mathrm{~nm}$ (FWHM) and the pulse duration is $750 \mathrm{fs}$, (assuming a $\operatorname{sech}^{2}$ temporal shape). The characterization of the beam profile reveals a good beam quality of $\mathrm{M}^{2}<1.3$ at $100 \mathrm{~W}$ of power.

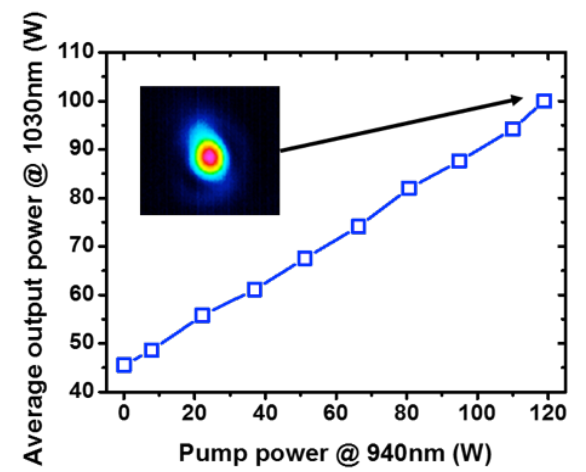

Fig. 7. Output power versus pump power in the last singlepass amplifier for $55 \mathrm{~W}$ of incident signal power in linear polarization.

In the case of the cylindrically polarized beam amplification, the self-focusing phenomenon induced by Kerr effect is not a limiting factor in our setup for several reasons. At the same power the peak intensity of a Gaussian distribution (linearly polarized) is about 1.36 times higher than the peak intensity of Laguerre Gauss beam (cylindrically polarized). In addition, the waist of the signal beam (calculated at $4 \sigma$ ) used in the setup with cylindrical polarization $(500 \mu \mathrm{m})$ was larger than the one with linear polarization $(400 \mu \mathrm{m})$. Moreover, the output power reached with linear polarization was higher than with the cylindrical polarization $(100 \mathrm{~W}$ instead of $86 \mathrm{~W}$ ). Taking into account these three factors, the peak intensity is three times lower in the case of the cylindrically polarized beam.

In conclusion, we have demonstrated the promising potential of SCF for the amplification of femtosecond pulses with different polarization states. By cascading a series of SCF amplifiers we achieved an average output power of $100 \mathrm{~W}$ in linear polarization and more than $85 \mathrm{~W}$ in both radial and azimuthal polarization. Remarkably, ultrashort pulses with duration of $750 \mathrm{fs}$ and pulse energies around $5 \mu \mathrm{J}$ have been generated without the need of chirped-pulse amplification without any issues by non-linear effect. To guarantee both high power and good beam quality, different strategies have been explored. On the first stage, specific optimization of doping and length of the SCF allowed significant improvement in terms of gain. Pumping the second amplifier at $969 \mathrm{~nm}$ instead of $940 \mathrm{~nm}$, reduces the thermal load by $30 \%$ and thus maintains the beam quality during the amplification. The high gain and the excellent conservation of both beam quality and polarization state make the SCF concept well suitable for the amplification of cylindrically polarized ultra-short pulses.

This study confirms the attractiveness of straightforward passive and CPA-free SCF amplifiers for ultrafast laser systems dedicated to industrial material processing applications.

This work is supported by The Ultrafast_RAZipol project funded by the European Union's Seventh Framework Program for research, technological development and demonstration under grant agreement no. 619237 .

\section{References}

1. R. Weber, A. Michalowski, M. Abdou Ahmed, V. Onuseit, V. Rominger, M. Kraus, and T. Graf, Physics Procedia 12, 21-30 (2011).

2. M. Kraus, M. Abdou Ahmed, A. Michalowski, A. Voss, R. Weber, and T. Graf, Opt. Exp. 18, N²1, 2305-22313, (2010).

3. M. A. Ahmed, M. Haefner, M. Vogel, C. Pruss, A. Voss, W. Osten, T. Graf, Opt. Exp. 19, 5093-5103 (2011).

4. M. Rumpel, M. Haefner, Th. Schoder, Opt. Lett. 37, 1763 (2012). M. Rumpel, M. Haefner, Th. Schoder, C. Pruss, A. Voss, W. Osten, M. Abdou Ahmed, and Th. Graf, Opt. Lett. 37, 1763-1765 (2012).

5. Florian Enderli and Thomas Feurer, Opt. Lett. 34, 2030-2032 (2009).

6. H. Jianhong, D. Jing, C. Yongge, W. Wen, Z. Hui, L. Jinhui, S. Fei, G. Yan, D. Shutao, L. Wenxiong, Opt. Express 19, 2120-2125 (2011).

7. T. Moser, J. Balmer, D. Delbeke, P. Muys, S. Verstuyft, R. Baets, Appl. Opt. 45(33), 8517-8522 (2006).

8. M. A. Ahmed, M. Vogel, A. Voss, and T. Graf, in CLEO Europe 2009, paper CA1_1.

9. P. Russbueldt, T. Mans, J. Weitenberg, H. D. Hoffmann, and R. Poprawe, Opt. Lett. 35, 4169 (2010).

10. M. Schulz, R. Riedel, A. Willner, T. Mans, C. Schnitzler, P. Russbueldt, J. Dolkemeyer, E. Seise, T. Gottschall, S. Hädrich, S. Duesterer, H. Schlarb, J. Feldhaus, J. Limpert, B. Faatz, A. Tünnermann, J. Rossbach, M. Drescher, and F. Tavella, Opt. Lett. 36, 2456 (2011).

11. A. V. Okishev, Opt. Lett. 37, 1199 (2012).

12. J. Negel, A. Voss, M. Abdou Ahmed, D. Bauer, D. Sutter, A. Killi, and T. Graf, Opt. Lett. 38, 54425445 (2013).

13. S. Piehler, X. Délen, M. Rumpel, J. Didierjean, N. Aubry, T. Graf, F. Balembois, P. Georges, M. A. Ahmed, Opt. Exp. 21, 11376 (2013). 
1. R. Weber, A. Michalowski, M. Abdou Ahmed, V. Onuseit, V. Rominger, M. Kraus, and T. Graf, "Effects of Radial and Tangential Polarization in Laser Material Processing," Physics Procedia 12, 21-30 (2011).

2. M. Kraus, M. Abdou Ahmed, A. Michalowski, A. Voss, R. Weber, and T. Graf, "Microdrilling in Steel using Ultrashort Pulsed Laser Beams with Radial and Azimuthal Polarization" Opt. Exp. 18, N²1, 2305-22313, 2010.

3. Marwan Abdou Ahmed, Matthias Haefner, Moritz Vogel, Christof Pruss, Andreas Voss, Wolfgang Osten, and Thomas Graf, "High-power radially polarized Yb:YAG thin-disk laser with high efficiency," Opt. Exp. 19, 5093-5103 (2011).

4. M. Rumpel, M. Haefner, Th. Schoder, Opt. Lett. 37, 1763 (2012). M. Rumpel, M. Haefner, Th. Schoder, C. Pruss, A. Voss, W. Osten, M. Abdou Ahmed, and Th. Graf, "Circular grating waveguide structures for intra-cavity generation of azimuthal polarization in a thin-disk laser," Opt. Lett. 37, 1763-1765 (2012).

5. Florian Enderli and Thomas Feurer, "Radially polarized mode-locked Nd:YAG laser," Opt. Lett. 34, 2030-2032 (2009)

6. Huang Jianhong, Deng Jing, Cao Yongge, Weng Wen, Zheng Hui, Li Jinhui, Shi Fei, Ge Yan, Dai Shutao, and Lin Wenxiong, "Passively modelocked radially polarized laser based on ceramic Nd:YAG rod," Opt. Express 19, 2120-2125 (2011)

7. Tobias Moser, Jürg Balmer, Danaë Delbeke, Peter Muys, Steven Verstuyft, and Roel Baets "Intracavity generation of radially polarized CO2 laser beams based on a simple binary dielectric diffraction grating," Appl. Opt. 45(33), 8517-8522 (2006).

8. M. Abdou Ahmed, M. Vogel, A. Voss, and T. Graf, "A $1-\mathrm{kW}$ radially polarized thin-disk laser," in CLEO/Europe and EQEC 2009 Conference Digest, (Optical Society of America, 2009), paper CA1_1.

9. P. Russbueldt, T. Mans, J. Weitenberg, H. D. Hoffmann, and R. Poprawe, "Compact diodepumped $1.1 \mathrm{~kW} \mathrm{Yb}: Y A G$ Innoslab femtosecond amplifier", Opt. Lett. 35, 4169 (2010).

10. M. Schulz, R. Riedel, A. Willner, T. Mans, C. Schnitzler, P. Russbueldt, J. Dolkemeyer, E. Seise, T. Gottschall, S. Hädrich, S. Duesterer, H. Schlarb, J. Feldhaus, J. Limpert, B. Faatz, A. Tünnermann, J. Rossbach, M. Drescher, and F. Tavella, "Yb:YAG Innoslab amplifier: efficient high repetition rate subpicosecond pumping system for optical parametric chirped pulse amplification", Opt. Lett. 36, 2456 (2011).

11. A. V. Okishev, "Highly efficient room-temperature $\mathrm{Yb}$ :YAG ceramic laser and regenerative amplifier" Opt. Lett. 37, 1199 (2012).

12. J. Negel, A. Voss, M. Abdou Ahmed, D. Bauer, D. Sutter, A. Killi, and T. Graf, "1.1 kW average output power from a thin-disk multipass amplifier for ultrashort laser pulses," Opt. Lett. 38, 54425445 (2013)
13. S. Piehler, X. Délen, M. Rumpel, J. Didierjean, N. Aubry, T. Graf, F. Balembois, P. Georges, M. A. Ahmed, "Amplification of cylindrically polarized laser beams in single crystal fiber amplifiers", Opt. Exp. 21, 11376 (2013). 